\title{
STABILITY ANALYSIS OF RUBBLE-MOUND BREAKWATERS UNDER TSUNAMI FIRST IMPACT AND OVERFLOW
}

Îñigo Aniel-Quiroga, Environmental Hydraulics Institute (IHCantabria), Universidad de Cantabria, anieli@unican.es

César Vidal, Environmental Hydraulics Institute (IHCantabria), Universidad de Cantabria, vidalc@unican.es

Mauricio González, Environmental Hydraulics Institute (IHCantabria), Universidad de Cantabria, gonzalere@unican.es

Javier L. Lara, Environmental Hydraulics Institute (IHCantabria), Universidad de Cantabria, jav.lopez@unican.es

\section{INTRODUCTION}

Tsunamis are relatively infrequent but very destructive phenomena that can cause devastating consequences on coastal areas. In view of recent tragic episodes, the scientific community is strengthening their efforts to develop strategies to mitigate the risk of tsunami consequences, specially focused on the potentially affected areas. One of the strategies in this direction is the design and construction of more efficient coastal structures. In this way, in the frame of the EU FP7 project ASTARTE physical experiments on rubble-mound breakwaters (RMB) under tsunami wave attack have been carried out in the IH Cantabria facilities in Santander, Spain. These experiments focused on gaining a better understanding of tsunami impacts on this kind of structures. Improving the knowledge about their stability and hydrodynamics will contribute to a better design of coastal protection marine structures.

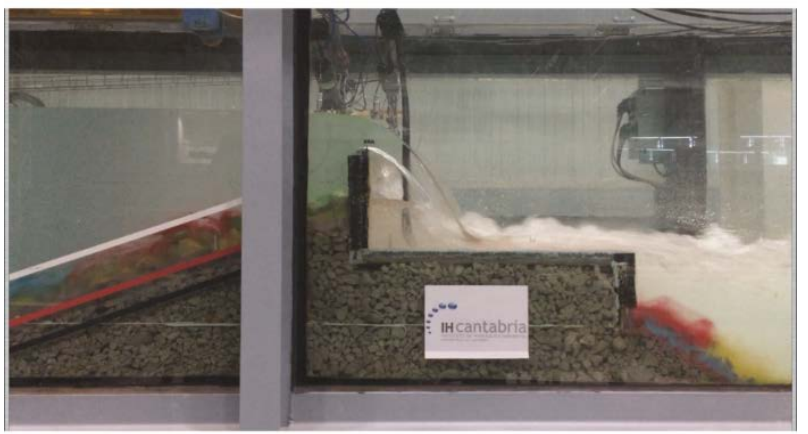

Figure 1.Overtopping over RMB with crown wall.

\section{CHARACTERISTICS OF THE EXPERIMENTS}

2-D Laboratory experiments have been carried out at 1:20 scale on two typical Mediterranean RMBs: (1) with crown wall (see figure 1) and (2) without crown wall (see figure 2). Two types of tsunami waves have been modelled: a) solitary waves, reproducing the effect of the impact of the first tsunami solitons and b) overtopping tests, generated using the flume current system, simulating a very long wave overflow over the breakwaters. Free surface, water velocities, crown wall pressures, core pressures and armor layers damage (using a laser profiler before and after each test) have been measured under different solitary wave heights and flow discharges.

\section{RESULTS}

Using these recorded data several variables were calculated for each test, focused on evaluating the stability of the structures under tsunami-like loads. Stability number (Ns), dimensionless damage level (S), normalized freeboard $(\mathrm{Fn})$ and number of waves $(\mathrm{N})$ have been calculated for the two tested RMBs, and a separate analysis has been accomplished for the seaside and the leeside slopes. After the damage analysis, several exponential fittings have been proposed for damage evolution of both slopes.

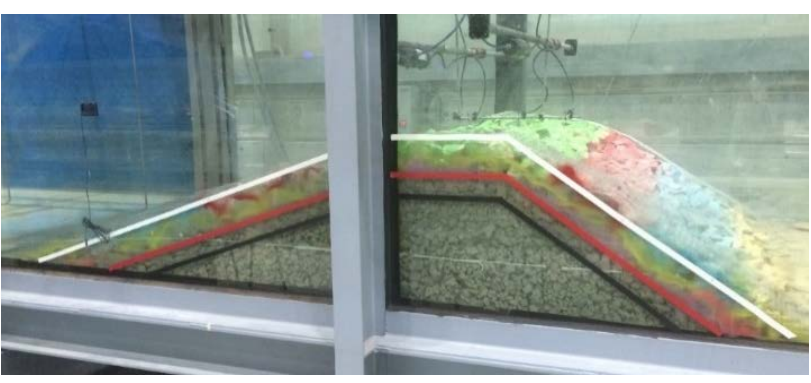

Figure 2.Lateral view of rubble-mound breakwater without crown wall

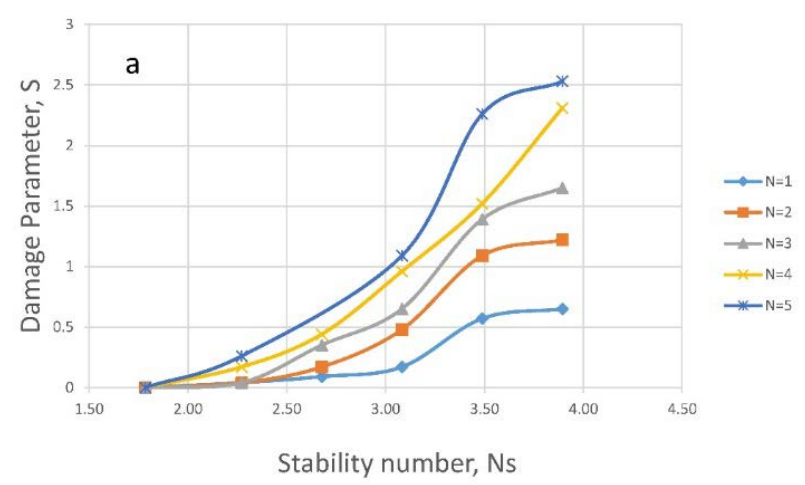

Figure 3. Damage parameter, $\mathrm{S}$, in terms of the stability number, Ns, for different number of waves, N. Results obtained in the seaside slope of type I RMB

The behavior of the RMB was noted different for tsunamis and wind waves. Based on these differences, new thresholds values for the dimensionless damage levels have been proposed for tsunamis, distinguishing the solitary wave and the overflow current actions.

The main characteristics of these novel laboratory tests, the methodology and the instrumentation applied, and the results of the stability and hydrodynamic analyses are presented in this work.

\section{ACKNOWLEDGMENT}

The research leading to these results has received funding from the EU's FP7 under grant agreement $n^{\circ} 603839$ (Project ASTARTE). 